\title{
Penilaian Kesesuaian Lahan Padi dan Jagung di Kecamatan Lewa Tidahu Kabupaten Sumba Timur
}

\author{
Yonce Melyanus Killa ${ }^{a}$
}

${ }^{a}$ Fakultas Sains dan Teknologi, Universitas Kristen Wira Wacana Sumba, Sumba Timur-NTT, Indonesia, email: yoncekilla7@gmail.com

\section{Article Info}

Article history:

Received 09 Februari 2020

Received in revised form 11 Juni 2020

Accepted 27 Oktober 2020

DOI:

https://doi.org/10.32938/sc.v5i04.999

Keywords:

Kesesuaian Lahan

Lewa Tidahu

Padi

Jagung

\section{Abstrak}

Kecamatan Lewa Tidahu adalah salah satu kecamatan di Kabupaten Sumba Timur Provinsi Nusa Tenggara Timur (NTT). Daerah ini adalah daerah yang sebagian besar usahataninya merupakan pertanian lahan kering dengan potensi lahan yang bisa dilakukan prog ram pengembangan tanaman padi dan jagung. Penelitian ini bertujuan untuk mengetahui karakteristik lahan dan kesesuain lahan untuk tanaman padi dan jagung di kecamatan Lewa Tidahu Kabupaten Sumba Timur. Penelitian ini dilaksanakan pada bulan Januari-Juni 2019. Metode analisis yang digunakan adalah metode pencocokan (Matching) adan metode overlay melalui extensions model builder dalam Software Arcview 3.2. Hasil analisis kesesuaian lahan dengan metode overlay karakteristik lahan, menunjukan kelas kesesuaian lahan tanaman padi adalah kelas kesesuaian S1 (Sangat Sesuai) 21.301 ha $(61,99 \%$ ), S2 (Cukup Sesuai) 12.859 ha (37,43\%) dan N (Tidak Sesuai) 199 ha $(0,58 \%)$. Kelas kesesuaian lahan tanaman jagung adalah kelas kesesuain S1 (Sangat Sesuai) 7.651 ha $(22,26 \%)$, S2 (Cukup Sesuai) 26.507 ha $(77,14 \%$ ), dan N (Tidak Sesuai) 201 ha $(0,60 \%)$. Hasil pencocokan dengan syarat tumbuh tanaman padi dan jagung memperoleh faktor pembatas utama yaitu ketersediaan oksigen (ao) seperti drainase dan kedalaman tanah, bahaya erosi (eh) atau lereng, penyiapan lahan $(l p)$ atau batuan di permukaan.

\section{Pendahuluan}

Tanaman padi dan jagung merupakan tanaman pangan yang selalu digunakan sebagai bahan konsumsi utama bagi masyarakat Indonesia. Hal ini dikarenakan sebagaian besar penduduk indonesia menjadikan padi sebagai bahan makanan utama dan jagung sebagai pengganti padi untuk dikonsumsi. Oleh karena itu, untuk meningkatkan produksi tanaman padi dan jagung, peperintah melaksanakan perbaikan sektor pertanian melalui program nasional swasembada pangan. Keberhasilan dalam pengembangan dan peningkatan komoditas pangan padi dan jagung di suatu daerah dapat terjadi bila telah diketahui kesesuaian karakteristik lahan dengan syarat tumbuh dari tanaman tersebut. Karakteristik lahan dari suatu wilayah dapat diketahui dengan melakukan evaluasi lahan. Evaluasi lahan merupakan suatu proses penilaian sumberdaya lahan untuk tujuan tertentu dengan menggunakan suatu pendekatan atau cara yang sudah teruji. Hasil evaluasi lahan akan memberikan informasi dan/atau arahan penggunaan lahan sesuai keperluan. Kesesuaian lahan adalah tingkat kecocokan sebidang lahan untuk penggunaan tertentu (Tumpubolon dkk., 2015). Fudhall dkk. (2016) menengaskan, evaluasi kesesuaian lahan merupakan salah satu komponen penting dalam proses perencanaan penggunaan lahan yang dipergunakan untuk perencanaan penggunaan lahan yang optimum dalam bentuk tata guna lahan. Lebih lanjut di jelaskan oleh (Arsyad, 2007) bahwa, evaluasi lahan merupakan penghubung antara berbagai aspek dan kualitas fisik, biologi dan teknologi penggunaan lahan dengan tujuan sosial ekonomi. Kesesuaian lahan diperlukan untuk budidaya tanaman agar mendapat pertumbuhan yang optimal, walaupun tanaman bisa tumbuh pada suatu lahan, akan tetapi belum tentu lahan tersebut sesuai untuk tanaman tertentu (Mutiara, 2015).

Evaluasi kesesuaian lahan seperti yang dianjurkan Food and Agriculture Organizarion (FAO) akan memberikan informasi tentang kelas kecocokan penggunaan suatu wilayah untuk komoditas tertentu. Kelas kesesuaian lahan terdiri dari: 1) kelas Sangat Sesuai (S1) yang menandakan bahwa lahan tidak memiliki faktor pembatas yang nyata terhadap produksi tanaman sehingga produktivitas mampu mencapai rentang 100-80 \% dari potensinya, 2) kelas Cukup Sesuai (S2) yang menunjukan bahwa lahan mempunyai faktor pembatas yang akan menurunkan produktivitas tanaman sehingga hanya mencapai hasil 80-60\% dari potensinya, 3) kelas Sesuai Marjinal (S3) yang menandakan bahwa lahan mempunyai faktor pembatas yang berat sehingga produktivitas tanaman hanya berkisar pada rentangan 60-40 \% dari potensinya, dan 4) kelas Tidak Sesuai $(\mathrm{N})$ yang mununjukan bahwa terdapat faktor pembatas yang sangat berat sehingga produktivitas tanaman hanya mencapai maksimal $40 \%$ dari potensinya (Banjarnahor \& Simanjuntak, 2016). Kecamatan Lewa Tidahu adalah salah satu kecamatan di Kabupaten Sumba Timur Provinsi Nusa Tenggara Timur (NTT). Daerah ini adalah daerah yang sebagian besar usahataninya merupakan pertanian lahan kering dengan potensi lahan yang bisa dilakukan program pengembangan tanaman padi dan jagung. Potensi lahan yang ada perlu diketahui lebih dalam agar dalam melakukan pengembangan tanaman padi dan jagung dapat memperoleh produksi yang maksimal. Oleh karena itu penelitian ini bertujuan untuk mengetahui kondisi karakteristik lahan dan kesesuaian lahan untuk tanaman padi dan jagung di kecamatan Lewa Tidahu Kabupaten Sumba Timur.

\section{Metode}

Pengambilan sampel tanah dan data primer dilaksanakan di Kecamatan Lewa Tidahu Kabupaten Sumba Timur Provinsi Nusa Tenggara Timur dan analisis sampel tanah di lakukan di Laboratorium Tanah, Fakultas Pertanian dan Bisnis Universitas Kristen Satya Wacana pada bulan Januari - Juni 2019. Alat yang digunakan dalam penelitian ini adalah GPS, plastik, kertas label, alat tulis, dan alat-alat laboratorium untuk analisis tanah, serta Sofware Arcview versi 3.2, QGIS versi 2.8. Bahan yang digunakan adalah bahan-bahan yang dipakai untuk menganalisis tekstur, draenase/redoks, pH, C-Organik, Daya
Hantar Listrik (DHL) / Electrical Conduktivity (EC), Kapasitas Tukar Kation (KTK) tanah. Metode analisis yang dilakukan yaitu:

a. Analisis Karakteristik Lahan (iklim dan tanah)

Mengumpulkan data karakteristik lahan untuk mengetahui kondisi iklim dan tanah Kecamatan Lewa. Data karakteristik lahan diperoleh dengan cara mengumpulkan data iklim (curah hujan dan suhu) serta mengambil dan menganalisis sampel tanah. Data curah hujan yang digunakan adalah data curah hujan tahun 2000 - 2017 yang diperoleh dari Badan Meteorologi, Klimatologi dan Geofisika Provinsi Nusa Tenggara Timur dan berasal dari 7 stasiun klimatologi di Kabupaten Sumba Timur (Wanga, Tanarara, Ngongi, Malahar, Kananggar, melolo dan Waingapu) dan 1 stasiun klimatologi di Kabupaten Sumba Tengah (Lindiwacu). Informasi tentang karakter tanah dipeoleh dengan cara mengambil sampel tanah dan analisis di laboratorium. Titik pengambilan sampel tanah dilakukan dengan metode simpel random sampling berdasarkan overlay peta yaitu peta penggunaan lahan, peta curah hujan, peta kemiringan lereng, peta jenis tanah dan peta administrasi. Penentuan jumlah sampel menggunakan tingkat ketelitian tinjau mendalam berdasarkan peta penggunaan lahan dengan mengeliminasi daerah non pertanian (terutama hutan dan padang sabana). Hasil penentuan memperoleh 27 lokasi titik sampel yang tersebar di seluruh wilaya Kecamatan Lewa Tidahu. Karakteristik tanah seperti kedalam tanah, batuan permukaan, bahan kasar diperoleh pada saat survey lapangan, sedangkan data karakteristik lahan seperti tekstur, draenase/redoks, $\mathrm{pH}$, C-Organik, daya hantar listrik (DHL), Kapasitas Tukar Kation (KTK) tanah diperoleh dari hasil analisi sampel tanah di Laboratorium Tanah Universitas Kristen Satya Wacana Salatiga.

b. Analisis Kesesuaian Lahan

Penilaian kesesuaian lahan dilakukan dengan menggunakan 2 (dua) metode, yaitu: 1) Metode Pencocokan atau Matching yaitu membandingkan antara karakteristik lahan sebagai parameter yang diukur di lapangan dan laboratorium dengan kriteria kesesuaian lahan yang disusun berdasarkan persyaratan tumbuh tanaman menurut informasi dari Djaenudin dkk., 2003); 2) Metode Overlay dilakukan dengan pemberian skor dan bobot yang berimbang pada karakteristik iklim dan tanaha melalui extensions modelbuilder dalam software Arcview 3.2 sehingga dapat ditentukan kelas kesesuaian lahan wilayah tersebut. Pemberian skor yang berimbang antara karakteristik iklim dan tanah dilakukan dengan asumsi bahwa karakteristik-karakteristik tersebut memiliki pengaruh yang sama terhadap kesesuaian lahan untuk tanaman. karakteristik iklim diberi skor 50 yang dibagi antara curah hujan dan suhu, sedangkan karakteristik tanah diberi skor 50 meliputi drainase, tekstur, bahan kasar, kedalaman efektif, KTK, pH, C-Organik, redoks, daya hantar listrik (DHL)/electrikal conduktivity (EC), kelerengan, dan batuan permukaan. Pembobotan dilakukan berdasarkan pada kesesuaian lahan tanaman padi dan jagung dengan nilai bobot 4 pada kesesuaian S1, bobot 3 pada kesesuaian S2, bobot 2 pada kesesuaian S3, dan bobot 1 pada kesesuaian $\mathrm{N}$.

\section{Hasil dan Pembahasan}

\section{Karakteristik lahan Kecamatan Lewa Tidahu}

Kecamatan Lewa Tidahu Kabupaten Sumba Timur Provinsi Nusa Tenggara Timur. Secara administratif, kecamatan Lewa Tidahu berbatasan dengan Kecamatan Lewa di sebelah Utara, Lautan Indonesia di sebelah Selatan, Kecamatan Katala Hamulingu di sebelah Timur, dan Kabupaten Sumba Tengah di sebelah Barat. Kecamatan Lewa memiliki luas wilayahnya \pm 29.390 ha yang terdiri dari 6 desa yaitu Desa Bidi Praing, Desa Watumbelar, Desa Umamanu, Desa Mondu Lambi, Desa Laihau, Desa Kangeli. Kecamatan Lewa Tidahu berada di daerah dataran rendah di sebelah selatan dengan ketinggian $14 \mathrm{~m} \mathrm{dpl}$ 
hingga ketinggian antara $532 \mathrm{~m}$ dpl (Badan Pusat Statistik (BPS), 2015). Berdasarkan analisis data dari 8 stasiun klimatologi diperoleh rata-rata curah hujan di Kecamatan Lewa Tidahu antara 1.360-1.949 mm/tahun. Suhu udara di kecamatan berkisar antara $23.9^{\circ} \mathrm{C}$ hingga $26,3^{\circ} \mathrm{C}$ menurut perhitungan dengan persamaan Braak (1928 dalam Djaenudin dkk. 2003).

Kondisi tanah wilayah penelitian sangat beragam, tekstur tanah terdiri dari liat, lempung berliat, dan lempung liat berdebu dengan kemasaman netral yaitu berkisar antara 5-7. Draenasi yang diketahui berdasarkan pengukuran potensial redoks termaksud dalam kondisi reduksi atau selalu tergenang saat tanah mengalami jenuh air. Kandungan C-Organik dan nilai kapasitas tukar kation (KTK) dalam tanah bervariasi dari rendah sampai sangat tinggi. Bahan kasar dan batuan permukaan di daerah pengamatan tergolong sangat sedikit hingga banyak. Salinitas tanah tergolong dalam kondisi non salinitas hingga rendah berdasarkan hasil pengukuran daya hantar listrik tanah (DHL). Kedalaman efektif tanah di daerah pengamatan bervariasi dari kelas dangkal hingga dalam. Kelerengan di daerah bervariasi dari datar hingga curam. Hasil pengukuran karakteristik tanah di wilayah kecamatan Lewa Tidahu berdasarkan Djaenudin dkk. 2003 dapat dilihat pada Tabel 1.

Tabel 1. Karakteristik lahan Kecamatan Lewa Tidahu

\begin{tabular}{|c|c|c|c|}
\hline \multicolumn{3}{|c|}{ Parameter } & Nilai Hasil Pengamatan \\
\hline \multicolumn{4}{|l|}{ Iklim } \\
\hline 1. & Suhu $\left({ }^{\circ} \mathrm{C}\right)$ & & $23.9-26,3^{\circ} \mathrm{C}$ \\
\hline 2. & Curah Hujan (mm/tahun) & & $1.360-1.949$ \\
\hline \multicolumn{4}{|l|}{ Tanah } \\
\hline 1. & Drainase & & Sangat terhambat \\
\hline 2. & Tekstur & & Halus dan sedang \\
\hline 3. & Bahan kasar (\%) & & $5-40$ \\
\hline 4. & Kedalaman tanah $(\mathrm{cm})$ & & 35 hingga $>75$ \\
\hline 5. & $\begin{array}{l}\text { Kapasitas } \\
(\mathrm{cmol} / \mathrm{kg})\end{array}$ & Kation & $\begin{array}{c}9,78-66,67 \\
1,36-7,11\end{array}$ \\
\hline 6. & C-Organik (\%) & & $5,80-7,10$ \\
\hline 7. & $\mathrm{pH}$ & & $<8->45$ \\
\hline 8. & Kelerengan (\%) & & $<3->25$ \\
\hline 9. & Batuan permukaan (\%) & & \\
\hline
\end{tabular}

Sumber : Data Hasil Analisis Tahun 2019

\section{Kelas Kesesuaian Lahan}

Evaluasi lahan merupakan suatu proses penilaian sumberdaya lahan untuk tujuan tertentu dengan menggunakan suatu pendekatan atau cara yang sudah teruji. Hasil evaluasi lahan akan memberikan informasi dan/atau arahan penggunaan lahan sesuai keperluan. Kesesuaian lahan adalah tingkat kecocokan sebidang lahan untuk penggunaan tertentu (Tumpubolon dkk., 2015). Lebih lanjut di jelaskan oleh Arsyad, (2007) bahwa, evaluasi lahan merupakan penghubung antara berbagai aspek dan kualitas fisik, biologi dan teknologi penggunaan lahan dengan tujuan sosial ekonomi. Hasil dari evaluasi lahan akan memberikan gambaran mengenai kelas kesesuaian lahan terhadap tanaman yang dibudidayakan. Kelas kesesuaian lahan ini diperoleh dengan cara mencocokan kriterian kesesuaian lahan untuk tanaman padi dan jagung dengan karakteristik wilayah kecamatan Lewa Tidahu. Kriteria kesesuaian lahan tanaman padi dan jagung dapat dilihat pada tabel 2 dan 3 .

Tabel 2. Kriteria Kesesuaian Lahan Untuk Tanaman Padi Tadah Hujan

\begin{tabular}{|c|c|c|c|c|}
\hline \multirow{2}{*}{$\begin{array}{c}\text { Persyaratan } \\
\text { Penggunaan/Karakteristik } \\
\text { Lahan }\end{array}$} & \multicolumn{4}{|c|}{ Kelas Kesesuaian Lahan } \\
\hline & S1 & S2 & S3 & $\mathrm{N}$ \\
\hline $\begin{array}{l}\text { Iklim } \\
\text { Temperatur }(\mathrm{tc}) \\
\text { Temperatur rerata }\left({ }^{\circ} \mathrm{C}\right)\end{array}$ & $24-29$ & $\begin{array}{l}22-24 \\
29-32\end{array}$ & $\begin{array}{l}18-22 \\
32-35\end{array}$ & $\begin{array}{l}<18 \\
>35\end{array}$ \\
\hline $\begin{array}{l}\text { Kerersediaan air (wa) } \\
\text { Curah hujan (mm) }\end{array}$ & $575-1.800$ & $\begin{array}{l}1.800-2.300 \\
405-575\end{array}$ & $\begin{array}{l}2.300- \\
2.850 \\
330-405\end{array}$ & $\begin{array}{l}>2.850 \\
<330\end{array}$ \\
\hline $\begin{array}{l}\text { Tanah } \\
\text { Ketersediaan oksigen (oa) } \\
\text { Drainase }\end{array}$ & $\begin{array}{l}\text { Terhambat, } \\
\text { agak terhambat }\end{array}$ & $\begin{array}{l}\text { Agak cepat, } \\
\text { sedang, baik }\end{array}$ & $\begin{array}{c}\text { Sangat } \\
\text { terhambat }\end{array}$ & Cepat \\
\hline $\begin{array}{l}\text { Media perakaran (rc) } \\
\text { Tekstur }\end{array}$ & $\begin{array}{l}\text { Halus, agak } \\
\text { halus, sedang }\end{array}$ & $\begin{array}{c}\text { Halus, agak } \\
\text { halus, sedang }\end{array}$ & $\begin{array}{l}\text { Agak kasar } \\
15-35\end{array}$ & $\begin{array}{c}\text { Kasar } \\
>35\end{array}$ \\
\hline $\begin{array}{l}\text { Bahan kasar }(\%) \\
\text { Kedalaman tanah }(\mathrm{cm})\end{array}$ & $\begin{array}{l}<3 \\
>50\end{array}$ & $\begin{array}{c}3-15 \\
40-50 \\
\end{array}$ & $25-40$ & $<25$ \\
\hline $\begin{array}{l}\text { Retensi hara (nr) } \\
\text { KTK liat (cmol) } \\
\text { pH } \mathrm{H}_{2} \mathrm{O} \\
\text { C-organik (\%) }\end{array}$ & $\begin{array}{c}>16 \\
5,5-8,2 \\
>1,5\end{array}$ & $\begin{array}{c}<16 \\
8,2-8,5 \\
0,8-1,5\end{array}$ & $\begin{array}{l}>8,5 \\
<0,8\end{array}$ & \\
\hline $\begin{array}{l}\text { Toksisitas (nr) } \\
\text { Salinitas (dS/m) }\end{array}$ & $<2$ & $2-4$ & $4-6$ & $>6$ \\
\hline $\begin{array}{l}\text { Bahaya lereng (eh) } \\
\text { Lereng }(\%)\end{array}$ & $<3$ & $3-8$ & $8-25$ & $>25$ \\
\hline $\begin{array}{l}\text { Penyiapan lahan (lp) } \\
\text { Batuan di permukaan }(\%)\end{array}$ & $<5$ & $5-15$ & $15-40$ & $>40$ \\
\hline
\end{tabular}

Sumber: Djaenudin dkk. (2003)
Tabel 3. Kriteria kesesuaian lahan untuk tanaman Jagung (Zea mays)

\begin{tabular}{|c|c|c|c|c|}
\hline \multirow{2}{*}{$\begin{array}{c}\text { Persyaratan } \\
\text { Penggunaan/Karakteristik } \\
\text { Lahan } \\
\end{array}$} & \multicolumn{4}{|c|}{ Kelas Kesesuaian Lahan } \\
\hline & S1 & S2 & S3 & $\mathrm{N}$ \\
\hline $\begin{array}{l}\text { Iklim } \\
\text { Temperatur }(\mathrm{tc}) \\
\text { Temperatur rerata }\left({ }^{\circ} \mathrm{C}\right)\end{array}$ & $20-26$ & $26-30$ & $\begin{array}{l}16-20 \\
30-32\end{array}$ & $\begin{array}{l}<16 \\
>32\end{array}$ \\
\hline $\begin{array}{l}\text { Kerersediaan air (wa) } \\
\text { Curah hujan tahunan (mm) }\end{array}$ & $500-1.200$ & $\begin{array}{c}1.200-1.600 \\
400-500\end{array}$ & $\begin{array}{l}>1.600 \\
300-400\end{array}$ & $<300$ \\
\hline $\begin{array}{l}\text { Tanah } \\
\text { Ketersediaan oksigen (oa) } \\
\text { Drainase }\end{array}$ & $\begin{array}{l}\text { baik, agak } \\
\text { terhambat }\end{array}$ & $\begin{array}{l}\text { Agak cepat, } \\
\text { sedang }\end{array}$ & terhambat & $\begin{array}{c}\text { Sangat } \\
\text { terhambat, } \\
\text { cepat }\end{array}$ \\
\hline $\begin{array}{l}\text { Media perakaran }(\mathrm{rc}) \\
\text { Tekstur } \\
\text { Bahan kasar }(\%) \\
\text { Kedalaman tanah }(\mathrm{cm})\end{array}$ & $\begin{array}{c}\text { Halus, agak } \\
\text { halus, sedang } \\
<15 \\
>60\end{array}$ & $\begin{array}{c}- \\
15-35 \\
40-60\end{array}$ & $\begin{array}{l}\text { Agak kasar } \\
35-55 \\
25-40\end{array}$ & $\begin{array}{l}\text { Kasar } \\
>55 \\
<25\end{array}$ \\
\hline $\begin{array}{l}\text { Retensi hara (nr) } \\
\text { KTK liat (cmol) } \\
\text { pH } \mathrm{H}_{2} \mathrm{O} \\
\text { C-organik }(\%) \\
\end{array}$ & $\begin{array}{c}>16 \\
5,8-7,8 \\
>0,4\end{array}$ & $\begin{array}{c}<16 \\
5,5-5,8 \\
7,8-8,2 \\
<0,4\end{array}$ & $\begin{array}{l}<5,5 \\
>8,2\end{array}$ & \\
\hline $\begin{array}{l}\text { Toksisitas (nr) } \\
\text { Salinitas (dS/m) }\end{array}$ & $<4$ & $4-6$ & $6-8$ & $>8$ \\
\hline $\begin{array}{l}\text { Bahaya lereng (eh) } \\
\text { Lereng }(\%)\end{array}$ & $<8$ & $8-16$ & $16-30$ & $>30$ \\
\hline $\begin{array}{l}\text { Penyiapan lahan (lp) } \\
\text { Batuan di permukaan }(\%)\end{array}$ & $<5$ & $5-15$ & $15-40$ & $>40$ \\
\hline
\end{tabular}

Sumber: Djaenudin dkk. (2003)

\section{Kesesuaian Lahan Tanaman Padi}

Berdasarkan hasil analisis kelas kesesuaian lahan metode overlay dengan menggunakan extension model builder pada software Arcview dengan pemberian skor dan bobot berimbang pada karakteristik lahan, diperoleh tiga kelas kesesuaian lahan tanaman padi di Kecamatan Lewa Tidahu (gambar 1) yaitu: Kelas kesesuaian S1 (Sangat Sesuai) 21.301 ha (61,99 \%), S2 (Cukup Sesuai) 12.859 ha $(37,43 \%)$ dan N (Tidak Sesuai) 199 ha $(0,58 \%)$. Dari hasil analisis terlihat bahwa Kecamatan Lewa Tidahu sebagian besar wilayahnya masih didominasi dengan kelas kesesuaian lahan S1 (Sangat Sesuai) untuk budidaya dan pengembangan tanaman padi. Akan tetapi untuk pengembangan lahan-lahan yang kesesuaiannya S2 (Cukup Sesuai) perlu dilakukan perbaikan terhadap faktor-faktor pembatas yang ada sehingga kesesuaiannya menjadi S1 (Sangat Sesuai). Hasil Matching parameter karakteristik lahan dengan kriteria kesesuaian lahan menurut Djaenudin dkk., (2003) diperoleh faktor pembatas utama yaitu 1) ketersediaan oksigen (ao) seperti drainase dan kedalaman tanah; 2) bahaya erosi (eh) atau lereng; 3) penyiapan lahan (lp) atau batuan di permukaan. Faktor pembatas drainase dapat menentukan jenis tanaman yang dapat tumbuh karena berhubungan dengan ketersediaan oksigen dalam tanah. Hardjowigeno (2007) mengatakan bahwa tanaman padi dapat hidup pada tanahtanah berdrainase buruk atau tergenang. Pada daerah dengan drainase sangat terhambat tidak berpengaruh karena tanaman padi mempunyai sistem pertukaran $\mathrm{O}_{2}$ internal akar-tajuk sehingga walaupun tergenang, mereka masih bisa berespirasi (Utomo dkk., 2016). Faktor pembatas kedalaman merupakan faktor pembatas yang tergolong permanen karena tidak dapat dilakukan perbaikan, apabila dipaksakan untuk perbaikan maka hanya dilakukan dengan penambahan bahan organik sebagai media tanam. Faktor pembatas batuan permukaan merupakan faktor pembatas yang bersifat permanen dan sulit untuk dilakukan perbaikan. Faktor pembatas kelerengan berkaitan dengan terjadinya erosi permukaan yang dapat menggurangi tingkat kesuburan lahan. Faktor kelerengan dapat diperbaharui dengan beberapa cara, salah satunya dengan membuat teras di daerah miring agar mengurangi terjadinya erosi (Juarsah dkk., 2008).

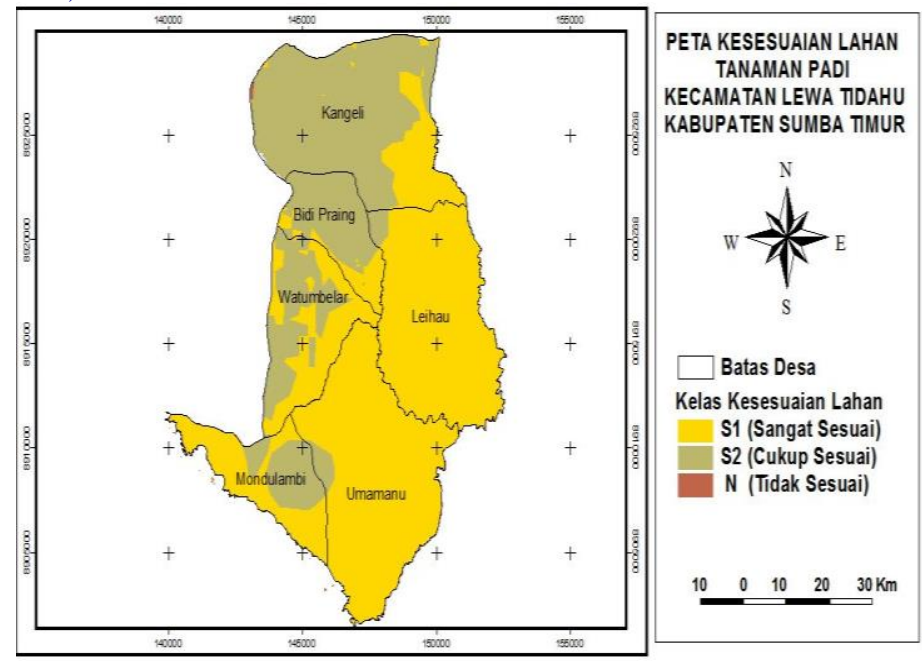

Gambar 1. Peta Kesesuaian Lahan Tanaman Padi 


\section{Kesesuaian Lahan Tanaman Jagung}

Berdasarkan hasil analisis kelas kesesuaian lahan metode overlay dengan menggunakan extension modelbuilder pada Software Arcview dengan pemberian skor dan bobot berimbang pada karakteristik lahan, diperoleh tiga kelas kesesuaian lahan tanaman jagung di Kecamatan Lewa Tidahu (gambar 2) yaitu: Kelas Kesesuaian S1 (Sangat Sesuai) 7.651 ha $(22,26 \%$ ), S2 (Cukup Sesuai) 26.507 ha $(77,14 \%)$, dan N (Tidak Sesuai) 201 ha $(0,60 \%)$. Kelas kesesuaian lahan S2 merupakan kelas kesesuaian yang dominan yang mencakup hampir seluruh wilayah kecamatan. Akan tetapi, untuk meningkatkan kelas kesesuaian lahan untuk tanaman jagung kekelas kesesuaian S1 diperlukan pengelolaan terhadap faktor-faktor pembatas yang ada. Hasil Matching parameter karakteristik lahan dengan kriteria kesesuaian lahan menurut Djaenudin dkk. (2003) diperoleh faktor pembatas utama yaitu 1) ketersediaan oksigen (ao) seperti drainase dan kedalaman tanah; 2) bahaya erosi (eh) atau lereng; 3) penyiapan lahan (lp) atau batuan di permukaan. Faktor pembatas ketersediaan oksigen dapat untuk drainase pada tanaman jagung dapat diperbaharui atau ditingkatkan kelas kesesuaiannya dengan usaha perbaikan irigasi dan pembuatan saluran drainase (Wirosoedarmo dkk., 2011) Drainase yang baik diperlukan oleh tanaman yang membutuhkan aerasi yang baik seperti jagung. Aerasi tanah yang baik menyebabkan di dalam tanah cukup tersedia oksigen. Dengan demikian, akar tanaman mampu menyerap unsur hara dan dapat berkembang dengan baik (Wirosoedarmo dkk., 2011). Perbaikan terhadap drainase perlu dilakukan karena tanaman jagung tidak akan tumbuh dengan baik kalau tanah selalu tergenang (Hardjowigeno, 2007). Faktor pembatas kedalaman merupakan faktor pembatas yang tergolong permanen karena tidak dapat dilakukan perbaikan, apabila dipaksakan untuk perbaikan maka hanya dilakukan dengan penambahan bahan organik sebagai media tanam. Faktor pembatas batuan permukaan merupakan faktor pembatas yang bersifat permanen dan sulit untuk dilakukan perbaikan. Faktor pembatas kelerengan berkaitan dengan terjadinya erosi permukaan yang salah satunya dapat menggurangi tingkat kesuburan lahan. Faktor pembatas bahaya erosi tanaman jagung dapat dikelola dengan pemotongan lereng dengan sistem teras gulud dan teras bangku untuk mengurangi erosi tanah (Wirosoedarmo dkk., 2011).

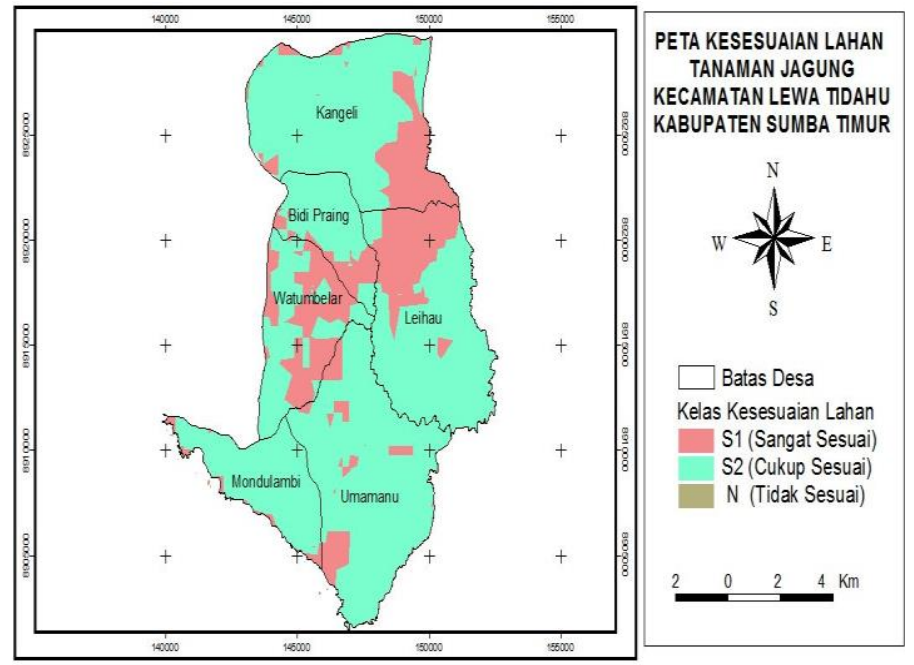

Gambar 2. Peta Kesesuaian Tanaman Jagung

\section{Simpulan}

Hasil Hasil survey dan analisis labiratorium menunjukkan bahwa karakteristik tanah di Kecamatan Lewa Tidahu bervariasi. Tekstur tanah terdiri dari liat, lempung berliat, dan lempung liat berdebu dengan kemasaman netral yaitu berkisar antara 5-7. Kandungan C-Organik dan nilai KTK dalam tanah bervariasi dari rendah sampai sangat tinggi. Bahan kasar dan batuan permukaan di daerah pengamatan tergolong sangat sedikit hingga banyak. Kedalaman efektif tanah di daerah pengamatan bervariasi dari kelas dangkal hingga dalam. Hasil analisis kesesuaian lahan dengan metode overlay karakteristik lahan, menunjukan kelas kesesuaian lahan tanaman padi adalah kelas kesesuaian S1 (Sangat Sesuai) 21.301 ha $(61,99 \%)$, S2 (Cukup Sesuai) 12.859 ha $(37,43 \%)$ dan N (Tidak Sesuai) 199 ha $(0,58 \%)$. Kelas kesesuaian lahan tanaman jagung adalah kelas kesesuain S1 (Sangat Sesuai) 7.651 ha $(22,26 \%)$, S2 (Cukup Sesuai) 26.507 ha $(77,14 \%)$, dan N (Tidak Sesuai) 201 ha $(0,60 \%)$. Hasil pencocokan dengan syarat tumbuh tanaman padi dan jagung memperoleh faktor pembatas utama yaitu ketersediaan oksigen (ao) seperti drainase dan kedalaman tanah, bahaya erosi (eh) atau lereng, penyiapan lahan (lp) atau batuan di permukaan
Pustaka

Atmojo Arsyad, S. (2007). Konservasi Tanah dan Air. Bogor: IPB Press.

Badan Pusat Statistik (BPS). (2015). Kabupaten Sumba Timur dalam Angka 2015. Kabupaten Sumba Timur: Badan Pusat Statistik.

Banjarnahor, D., \& Simanjuntak, B. H. (2016). Evaluasi Kesesuaian Lahan Sumba Tengah untuk Tanaman Pangan Serta Perancangan Pola Tanamnya Yang Spesifik Lokasi. Bumi Lestari, 16(2), 108-118.

Djaenudin, D., H, M., H, S., \& Hidayat, A. (2003). Petunjuk Teknis Evaluasi Lahan untuk Komoditas Pertanian. Bogor: Balai Penelitian Tanah, Puslitbang tanak.

Fudhall, M., Paloloang, A. K., \& Rahman, A. (2016). Evaluasi Kesesuaian Lahan untuk Pengembangan Tanaman Cengkeh (Eugenia aromatica L) Di Desa Marowo dan Bonevoto Kecamatan Ulubongka Kabupaten Tojo Una-Una. E-J. Agrotekbis, 4 (2), 142-150.

Hardjowigeno, S. (2007). Ilmu Tanah. Jakarta: Akademika Pressindo.

Juarsah, I., Yustika, R. D., \& Abdurachman, A. (2008). Pengendalian erosi dan kahat bahan organik tanah pada lahan kering berlereng mendukung produksi pangan nasional. In Seminar Nasional dan Dialog Sumberdaya Lahan Pertanian (pp. 18-20). Bogor: Balai Besar Penelitian dan Pengembangan Sumberdaya Lahan Pertanian.

Mutiara, E. (2015). Kesesuaian Lahan Untuk Tanaman Kacang Tanah di Desa Sampuran, Kecamatan Ranto Baek, Kabupaten Mandailing Natal. Nasional Ecopedon, 2(2), 1-4.

Tumpubolon, K., Razali, \& Guchy, H. (2015). Evaluasi Kesesuaian Lahan Tanaman Padi Sawah Irigasi (Oryza sativa L.) di Desa Bakaran Batu Kecamatan Sei Baban Kabupaten Serdang Bedagi. Jurnal Online Agroekoteknologi, 3(2), 732-739.

Utomo, M., Sabrina, T., Sudarsono, Lumbanraja, J., Rusman, B., \& Wawan. (2016). Ilmu Tanah: Dasar-dasar dan Pengelolaan. Jakarta: Prenada media Group.

Wirosoedarmo, R., Sutanhaji, A. T., Kurniati, E., \& Wijayanti, R. (2011). Evaluasi kesesuaian lahan untuk tanaman jagung menggunakan metode analisis spasial. Agritech, 31(1), 71-78. https://doi.org/https://doi.org/10.22146/agritech.9728 